University of Nebraska - Lincoln

DigitalCommons@University of Nebraska - Lincoln

Faculty Publications from the Department of Electrical \& Computer Engineering, Department Electrical and Computer Engineering

10-15-1988

\title{
Thin-film hermeticity: A quantitative analysis of diamond-like carbon using variable angle spectroscopic ellipsometry
}

\author{
S. Orzeszko \\ University of Nebraska-Lincoln \\ Bhola N. De \\ University of Nebraska-Lincoln \\ John A. Woollam \\ University of Nebraska-Lincoln, jwoollam1@unl.edu \\ John J. Pouch \\ NASA Lewis Research Center, Cleveland, Ohio \\ Samuel A. Alterovitz \\ NASA Lewis Research Center, Cleveland, Ohio \\ See next page for additional authors
}

Follow this and additional works at: https://digitalcommons.unl.edu/electricalengineeringfacpub

Part of the Electrical and Computer Engineering Commons

Orzeszko, S.; De, Bhola N.; Woollam, John A.; Pouch, John J.; Alterovitz, Samuel A.; and Ingram, David C., "Thin-film hermeticity: A quantitative analysis of diamond-like carbon using variable angle spectroscopic ellipsometry" (1988). Faculty Publications from the Department of Electrical and Computer Engineering. 48.

https://digitalcommons.unl.edu/electricalengineeringfacpub/48

This Article is brought to you for free and open access by the Electrical \& Computer Engineering, Department of at DigitalCommons@University of Nebraska - Lincoln. It has been accepted for inclusion in Faculty Publications from the Department of Electrical and Computer Engineering by an authorized administrator of DigitalCommons@University of Nebraska - Lincoln. 


\section{Authors}

S. Orzeszko, Bhola N. De, John A. Woollam, John J. Pouch, Samuel A. Alterovitz, and David C. Ingram 
Published in Journal of Applied Physics 64:8 (October 15, 1988), pp. 4175-4180

Submitted January 11, 1988; accepted July 5, 1988

\title{
Thin-film hermeticity: A quantitative analysis of diamondlike carbon using variable angle spectroscopic ellipsometry
}

\author{
S. Orzeszko, Bhola N. De, and John A. Woollam \\ Department of Electrical Engineering, University of Nebraska, Lincoln, Nebraska 68588-0511 \\ John J. Pouch and Samuel A. Alterovitz \\ NASA Lewis Research Center, Cleveland, Ohio 44135 \\ David C. Ingram \\ Universal Energy Systems, Dayton, Ohio 45432
}

\begin{abstract}
The purpose of this paper is twofold. First, we report on the successful application of variable angle spectroscopic ellipsometry to quantitative thin-film hermeticity evaluation. Secondly, it is shown that under a variety of film preparations and moisture introduction conditions water penetrates only a very thin diamondlike carbon (DLC) top surface-roughness region. Thus DLC is an excellent candidate for use as protective coatings in adverse chemical and aqueous environments.
\end{abstract}

Journal of Applied Physics is copyrighted by The American Institute of Physics.

DOI: $10.1063 / 1.341331$

Online at http://ink.aip.org/link/?JAPIAU/64/4175/1 


\title{
Thin-film hermeticity: A quantitative analysis of diamondilike carbon using variable angle spectroscopic ellipsometry
}

\author{
S. Orzeszko, Bhola N. De, and John A. Woollam \\ Department of Electrical Engineering, University of Nebraska, Lincoln, Nebraska 68588.0511 \\ John J. Pouch and Samuel A. Alterovitz \\ NASA Lewis Research Center, Cleveland, Ohio 44135 \\ David C. Ingram ${ }^{b>}$ \\ Universal Energy Systems, Doyton, Ohio 45432
}

(Received 11 January 1988; accepted for pubiication 5 July 1988)

\begin{abstract}
The purpose of this paper is twofold. First, we report on the successful application of variable angle spectroscopic ellipsometry to quantitative thin-film hermeticity evaluation. Second, it is shown that under a variety of film preparations and moisture introduction conditions water penetrates only a very thin diamondlike carbon (DLC) top surface-roughness region. Thus DLC is an excellent candidate for use as protective coatings in adverse chemical and aqueous environments.
\end{abstract}

\section{INTRODUCTION}

One of the most common uses of thin-film coatings is to prevent moisture penetration to an underiying surface. However (especially for very thin films), in is very difficuit to quantitatively measure the penetration of a film by water. Common techniques for thin-nilm and near-surface evaluation such as electron spectroscopy for chemical analysis (ESCA), Auger, secondary ion mass spectroscopy (SIMS), and various ion bean analysis techniques cannot be used because moisture and high vacuum are incompatible.

In this paper we show that variable angle spectroscopic ellipsometry (VASE) can be used to detect the thickness of wltrathin layers of water both on a surface and penetrated into a surface. The technique has monolayer sensitivity, can be used at any ambient pressure (including atmospheric), and is fast and nondestructive. ${ }^{1-4}$

The material studied presently is diamondlike carbon (DLC), otherwise known as "hydrogenated amorphous carbon." DLC films are generally hard, semitransparent materials with properties that can be controlled by the deposition parameter settings, which in turn determine the amount of hydrogen contained in the films. DLC films are usually not affected by strong acids or by common organic solvents and are thus good candidates for use as protective coatings. They are totally amorphous so they lack grain boundaries through which moisture might otherwise penetrate. There has been frequent confusion recently because of a parallel development of diamond thin films. ${ }^{5}$ The latter are films of polycrystalline diamonds containing very little hydrogen. Hard films of DLC, on the other hand, contain varying amounts of hydrogen and are amorphous. ${ }^{6-8}$ Both DLC and diamond films are hard and transparent in much of the visible, thus the "DLC," terminology. DLC films have been, and are continuing to be, extensiveiy studied. ${ }^{9}$ The purpose

\footnotetext{
an leave from N. Cupernicus University, Torun, Poland.

b) Now at Whickham Ion Beam Systems, Ltd., Neweastle-Upon-Tyne, Great Britain.
}

of the present paper is to present results of quantitative analysis of hermeticity studies of DLC films using VASE.

\section{H. EXPERMENT}

DLC films were prepared in a $30 \mathrm{kHz}$ parallel-plate plasma deposition chamber using pure methane gas and a chamber pressure of $\sim 20$ mTorr (Ref. 10). Power levels from 100 to $300 \mathrm{~W}$ were used, and substrate temperatures from 23 to $250^{\circ} \mathrm{C}$. The plates were equal in area with $20 \mathrm{~cm}$ diam. and $2 \mathrm{~cm}$ separation. Deposition rates ranged up to $250 \AA$ per min depending on power and temperature. Figure 1 shows deposition rate versus substrate temperature for three power levels and associated fow rates. Replots of the same data show that there is a linear relationship between deposition rate and fow rate. We find that there is no apparent relationship between power level and deposition rate. Thus the gas flow rate dominated over the power level in determining the deposition rate. All samples for these hermeticity studies were deposited on polished single-crystal silicon wafers.

Elipsometry measurements were made with a rotating analyzer system combining a variable angle of incidence

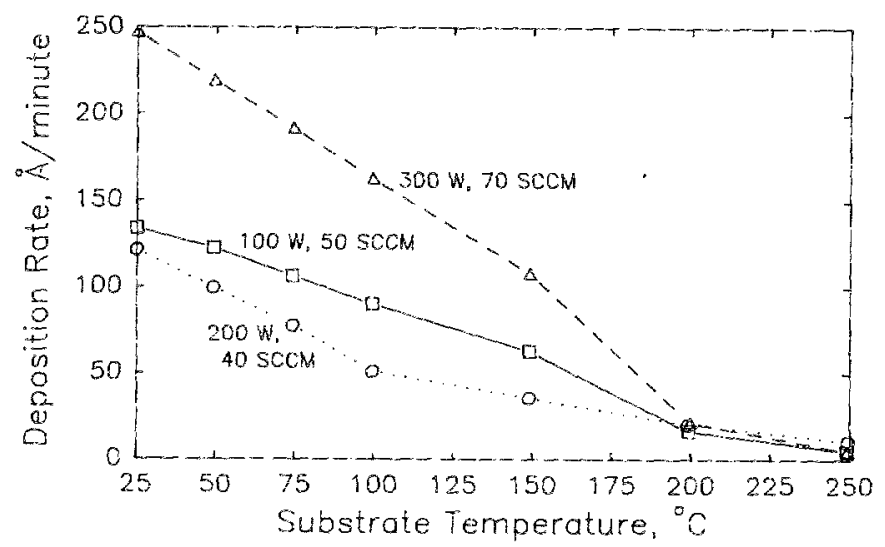

FIG. 1. Deposition rate vs substrate temperature for three different power level/fow-rate setrings. 


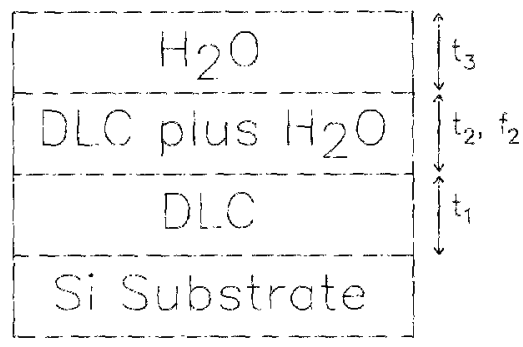

FIG. 2. Structure model assumed for analysis of DLC maisture studies.

with spectroscopic ( 3000 to $8500 \AA$ ) capabilities. ${ }^{1-4}$ This system has linearly polarized light (at a controlled azimuthal angle) incident on a sample at an angle $\phi$ to the normal. The amplitude and phase (or equivalently, azimuthal angle and ellipticity) of the reflected waye is analyzed with a second linear polarizer rotating at $50 \mathrm{~Hz}$. The signal detected by a photomultiplier tube is digitized, and a Fourier analysis of the amplitude and modulation is performed to determine the complex reffection ratio of $\rho$ defined by

$$
\rho=R_{p} / R_{s} \equiv \tan \psi \exp j \Delta,
$$

where $R_{p}$ and $R_{s}$ are the complex Fresnel reflection coefficients for the components parallel and perpendicular to the plane of incidence, respectively, for the material system, and the measured ellipsometric parameters $\psi$ and $\Delta$ are defined by Eq. (1).

Microstructural analysis is performed by making an assumption as to the nature of the sample under study. For the present samples the model is shown in Fig. 2. The $t_{i}$ are the layer thicknesses, and $f_{2}$ is the fraction of OLC in a DLC plus $\mathrm{H}_{2} \mathrm{O}$ Bruggeman effective medium approximation (EMA) mixture layer. "The procedure is to calculate $\rho$ using Fresnel reflection coefficients for a muitilayer parallel stack (and EMA mixed layers) for a given initial set of values for thicknesses and fractions. Next, a regression analysis is performed to minimize the error function (MSE) defined by

$$
\mathrm{MSE}=\frac{1}{N} \sum_{i=1}^{N}\left(\psi_{i}^{\text {exp }}-\psi_{i}^{\text {caic }}\right)^{2}+\left(\Delta_{i}^{\text {exp }}-\Delta_{i}^{\text {calc }}\right)^{2},
$$

where "exp" means experimentally measured, and "calc" means calculated. The psi and delta are functions of wavelength $\lambda$ and angle of incidence $\phi$. A large enough range of both $\lambda$ and $\phi$ are chosen so that an "overcietermination" of the number of measurements with respect to the number of unknown parameters is made and correlation problems are avoided. In our analysis programs we can use Eq. (2) as formulated, or we can use psi alone or deita alone in the analysis. The final outcome of the analysis is a set of valnes for thicknesses, EMA fractions, and optical constants for any of the layers. The optical constant values can take several forms: (1) index of refraction $n$ and extinction coefficient $k,(2)$ real, $E 1$, and imaginary, $E 2$, parts of the optical dielectric function, or (3) the amplitude, position, and width of Lorentz oscillators representing the absorption and dispersion of the material.

Since the Lorentz oscillator model was used extensively in this analysis we will describe it further. When the wavelength-dependent $n_{3} k$ (or $E 1, E 2$ ) values are solved, the number of unknown parameters equals the number of wave- lengths times two plus the number of layers plus the number of unknown fractions in an EMA. Thus if 20 wavelengths are used and there are two unknown thicknesses there will be $(2 \times 20)+2=42$ unknowns to be solved. In the Lorentz oscillator model there are far fewer unknowns, since the following equation represents the spectral dependence of optical constants ${ }^{12}$ :

$$
E=1+\sum_{i=1}^{M} A_{i}\left(\frac{1}{\lambda+P_{i}+j W_{i}}-\frac{1}{\lambda-P_{i}+j W_{i}}\right)
$$

where $E$ is the complex dielectric function, and the sum is over the total number of oscillators $M$. For the presently reported work, the maximum number of oscillators we used was one. In Eq. (3), $A_{i}, P_{i}$, and $W_{i}$ are the amplitude, position, and width of the ith oscillator, respectively, and $\lambda$ is the photon wavelength. In the oscillator anaiysis $A_{i}, P_{i}$, and $W_{i}$ thicknesses and EMA fractions are solved for in the regression analysis. Thus a typical one oscilator DLC analysis has five unknowns: three oscillator parameters and two layer thicknesses; or seven unknowns: three oscillator parameters, three layer thicknesses, and an EMA fraction (see the structural model shown in Fig. 2).

\section{RESUETS}

\section{A. General}

Figure 3 shows the dependence of the average (the index varies by less than $20 \%$ from 3000 to $8000 \AA$ ) index of refraction $n$ on substrate temperature for three different plasma power levels. As shown, the index rises from a value near 1.75 to near 2.0 and then shows evidence of a decrease to 1.93 for the $250^{\circ} \mathrm{C}$ sample. Similar results were reported by Alterovitz et al. ${ }^{10}$ In Fig. 4 the percentage of hydrogen (as determined by proton recoil analysis) is plotted as a function of deposition temperature. Notice the gradual decline, with a slight increase at the highest temperature. The trends in Figs. 3 and 4 are in the opposite directions; lower hydrogen concentration results in a higher index of refraction and films with more hydrogen are optically less dense.

From analysis of optical absorption data we know that the optical band gap inereases with increasing hydrogen con-

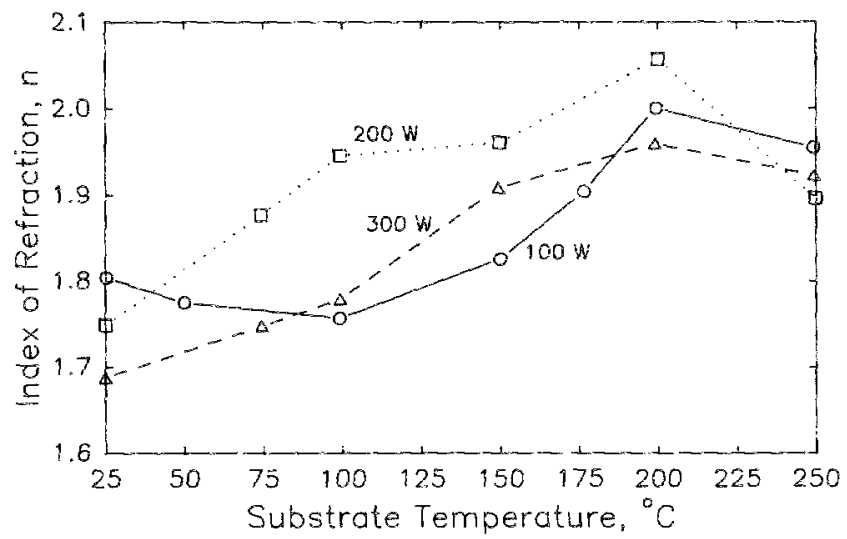

FrG. 3. Optical index of refraction vs substrate temperature for three different power levels. 


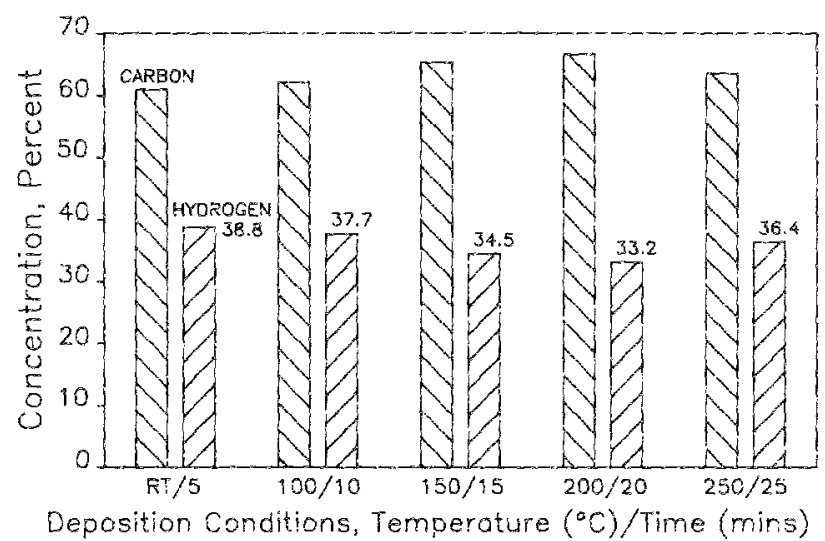

FIG. 4. Percent carbon and percent hydroger for samples deposited at room temperature (RT) to $250^{\circ} \mathrm{C}$.

centration. Thus the index of refraction (for green and longer wavelengths, where $k$ is zero) will decrease for films with greater band gap.

One final observation: we find that there is a slight de. cline in the index of refraction for films thicker than about $1000 \AA$. This suggests a "snow pile" effect; the latest DLC to deposit is less dense than the initial material deposited near the substrate interface.

To determine the environmental stability of DLC films we have deposited a large number of samples (at various power and temperature values) onto polished silicon singlecrystal wafers and subjected them to immersions in trichiorethane, acetone, ethyl alcohol, sulfuric acid, nitric acid, hy. drochloric acid, and hydrofuoric acid. After each immersion the samples were subjected to rubber eraser abra. sion tests and "scotch tape" pull tests. Although barely qualitative, the latter tests served as a valuable comparative measurement. These tests had no effect on any sample deposited with $100 \mathrm{~W}$. At 200 - and $300-\mathrm{W}$ depositions there was partial removal for samples deposited at roorn temperature, but there was no effect for substrate temperatures of 74 to $250^{\circ} \mathrm{C}$. Thus DLC samples prepared under all but a few conditions survived very stressing environmental tests.

\section{Room-temperiture noisture effects on $(200 \mathrm{~W}$, $250^{\circ} \mathrm{C}$ deposited) DLC films: One Lorentz Osclilator analysis}

Moisture was introduced to the DLC films on silicon wafer substrates at two temperatures: room temperature and at $100^{\circ} \mathrm{C}$. In this section the following studies were made.

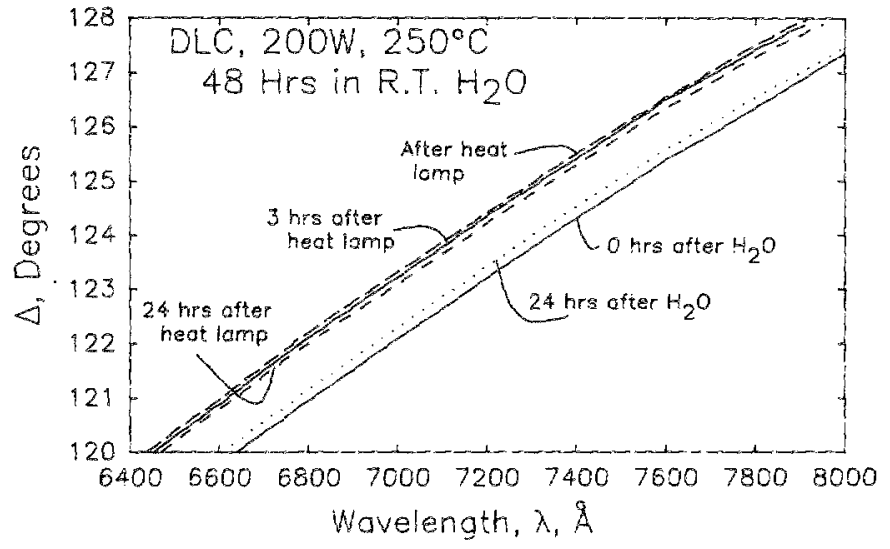

FIG. 5. Elipsometric delta parameter vs wavelength at various times after removing the sample from water, as listed. Sample deposited at $200 \mathrm{~W}$, $250^{\circ} \mathrm{C}$, soaked in room temperature water for $48 \mathrm{~h}$. After removing from water, it was kept in a room atmosphere.

The sample was prepared at $200 \mathrm{~W}$ in pure methane with a silicon substrate heated to $250^{\circ} \mathrm{C}$. The sample was then soaked in water at room temperature for $48 \mathrm{~h}$. Ellipsometric data were taken after the following sequence of steps:

(1) Immediately after being taken out of water.

(2) $24 \mathrm{~h}$ after being taken out of water.

(3) After applying a heat lamp for 15 min.

(4) 3 h after applying the heat lamp.

(5) $24 \mathrm{~h}$ after applying the heat lamp.

The results were analyzed using both a two-layer ("DLC" plus water layer: $t_{2}=0 \mathrm{in}$ Fig. 2) and a three-layer model [DLC, water plus DLC, and water layer (nonzero $t_{1}$, $t_{2}$, and $t_{3}$ layers in Fig. 2)].

Plots of the ellipsometrically measured delta parameters as a function of wavelength are shown in Fig. 5 for steps (1)(5) indicated above. Notice the sequence: delta increases as water leaves the surface. After $3 \mathrm{~h}$ (and then $24 \mathrm{~h}$ ) in a laboratory environment moisture redeposits.

Using the "oscillator" regression analysis and a twolayer model we determined that the water layer was $66-\AA$ thick on top of a $344-\AA$ thick DLC film. The three-layer mode 1 analysis was consistent with this result: $330 \AA$ of DLC, $29 \AA$ of $50 \%-50 \%$ mixture of DLC and water, and 48 $\AA$ of pure water on top.

An interesting result was that the heat lamp removed only $12 \AA$ of water and that $54 \AA$ of water still remained! We propose that this thin water layer is being held to the surface by an ususually high surface tension associated with DLC surface micropores.

TABLE I. Ellipsometric analysis of room-temperature water penetration in $\mathrm{DLC}\left(200 \mathrm{~W}, 250^{\circ} \mathrm{C}\right.$ deposited $)$.

\begin{tabular}{|c|c|c|c|c|c|}
\hline $\begin{array}{c}\text { Procedure } \\
\text { step/number }\end{array}$ & \multicolumn{2}{|c|}{ Two-layer analysis } & \multicolumn{3}{|c|}{ Three-layer analysis } \\
\hline 1 & $344 \AA$ & $66 \mathrm{~A}$ & $330 \AA$ & $29 \AA$ & $48 \AA$ \\
\hline 2 & 344 & 62 & 330 & 30 & 44 \\
\hline 3 & 341 & 54 & 330 & 24 & 40 \\
\hline 4 & 342 & 54 & 330 & 25 & 39 \\
\hline
\end{tabular}




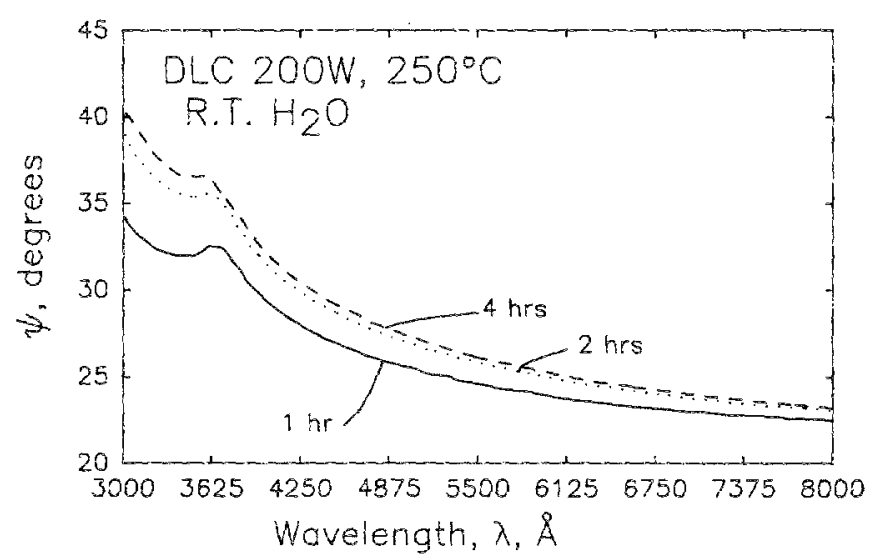

FIG. 6. Ellipsometric psi parameter vs wavelength for samples soaked for 1 to $4 \mathrm{~h}$ in room-temperature water.

Resuits of tine present ellipsometric analysis are summarized in Table $\mathrm{l}$.

We would like to propose that the "mixture" layer in the three-layer analysis is a roughness layer rather than a true material mixture. The water is just filling the spaces in the roughness region in this interpretation. A roughness layer of approximately $30 \AA$ is entirely reasonable.

\section{Moisture effects on (200 W, $250^{\circ} \mathrm{C}$ deposited) OLC fims: Room-temperature water and $100^{\circ} \mathrm{C}$ water}

In this section we present results of two-layer and threelayer analyses of both room-temperature water and $100^{\circ} \mathrm{C}$ water for samples deposited at $200 \mathrm{~W}$ and $250^{\circ} \mathrm{C}$. Ellipsometric psi and delta data are shown in Figs. 6 and 7 for roomtemperature water, and Figs. 8 and 9 for $100^{\circ} \mathrm{C}$ water. The graphs show trends after 1,2 , and $4 \mathrm{~h}$ soaking before measurement.

The results of the analysis of the data shown in Figs. 6-9 are shown in Table $\mathrm{II}$ (for room-temperature water) and in Table III (for $100^{\circ} \mathrm{C}$ water). In these tables "Mixture" indicates $50 \%$ water and $50 \%$ DLC. Several important points should be noticed: (1) For both room-temperature and $100^{\circ} \mathrm{C}$ water the measured water layer thickness increases for longer time in water, a conclusion independent of

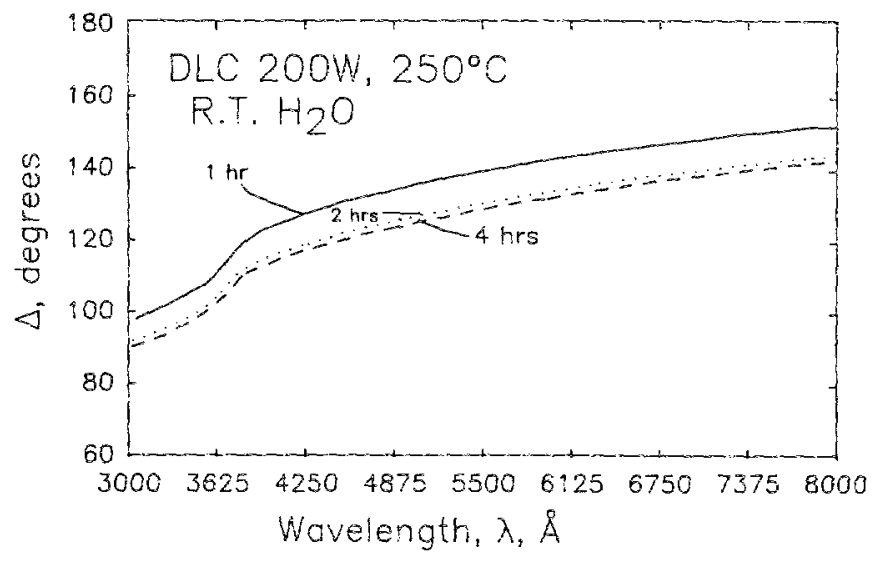

FIG. 7. Ellipsometric delta parameter, same conditions as in Fïg. 6.

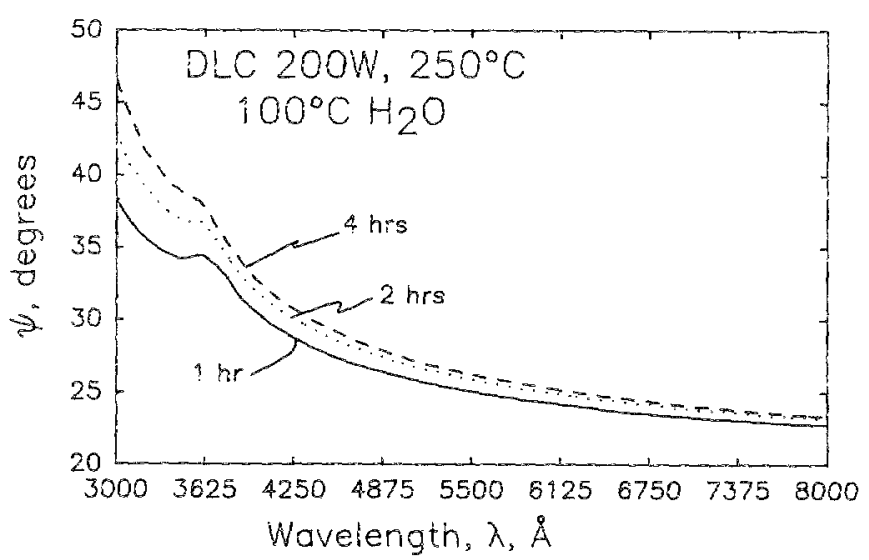

FIG. 8. Elipsometric psi parameter vs wavelength for samples soaked in $100^{\circ} \mathrm{C}$ water for 1 to $4 \mathrm{~h}$.

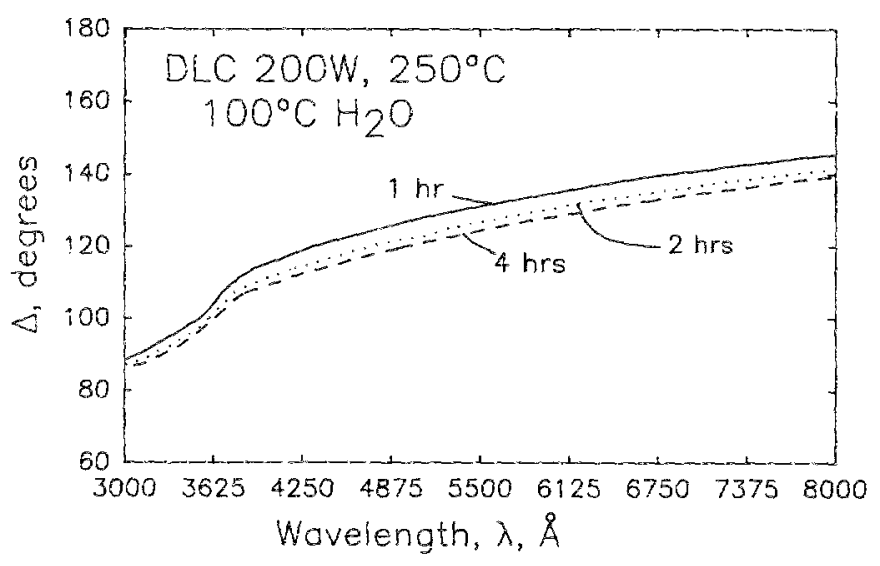

FIG. 9. Ellipsometric delta parameter vs wavelength for samples soaked in $100{ }^{\circ} \mathrm{C}$ water for $1-4 \mathrm{~h}$.

TABLE II. $200 \mathrm{~W}, 250^{\circ} \mathrm{C}$ sample in room-temperature water.

\begin{tabular}{lccccc}
\hline & \multicolumn{2}{c}{ Two-layer analysis } & & \multicolumn{2}{c}{ Three-layer analysis } \\
\cline { 2 - 3 } Condition & DLC & Water layer & DLC & Mixfure & Water layer \\
\hline Nowater & $328 \AA$ & $\cdots$ & $\cdots$ & $\cdots$ & $\cdots$ \\
2 hin water & $332 \AA$ & $57 \AA$ & $326 \AA$ & $24 \AA$ & $37 \AA$ \\
4 hin water & $336 \AA$ & $72 \AA$ & $328 \AA$ & $28 \AA$ & $51 \AA$ \\
\hline
\end{tabular}

TABLE III. $200 \mathrm{~W}, 250^{\circ} \mathrm{C}$ sample in $100^{\circ} \mathrm{C}$ water.

\begin{tabular}{lccccc}
\hline & \multicolumn{2}{c}{ Two-layer analysis } & & \multicolumn{2}{c}{ Threc-layer analysis } \\
\cline { 2 - 4 } \cline { 5 - 6 } Condition & DLC & Water layer & DLC & Mixture & Water layer \\
\hline Nowater & $328 \AA$ & $\ldots$ & $\ldots$ & $\ldots$ & $\cdots$ \\
2h in water & $360 \AA$ & $63 \AA$ & $337 \AA$ & $46 \AA$ & $36 \AA$ \\
$4 \mathrm{~h}$ in water & $361 \AA$ & $93 \AA$ & $339 \AA$ & $54 \AA$ & $56 \AA$ \\
\hline
\end{tabular}


TABLE IV. Moisture penetration studies (water) of 200.W plasma deposited DLC, one-oscillator model: ostillator parameters [see Eq. (3)] are in the sequence $A_{i}, P_{i}, W_{i}$ (measured in $\mathrm{eV}$ ). For definition of $t_{1}, i_{2}$, and $t_{3}$, see Fig. 2. (If $t_{2}$ and/or $t_{3}$ do not appear, then they are assumed to be equal to zero).

\begin{tabular}{|c|c|c|c|c|c|}
\hline$R T$ & $75^{\circ} \mathrm{C}$ & $100^{\circ} \mathrm{C}$ & $150^{\circ} \mathrm{C}$ & $200^{\circ} \mathrm{C}$ & $250^{\circ} \mathrm{C}$ \\
\hline \multicolumn{6}{|c|}{ 200-W DLC samples without $\mathrm{H}_{2} \mathrm{O}$} \\
\hline \multicolumn{6}{|c|}{$\begin{array}{c}200 \text {-W DLC samples with } \mathrm{H}_{2} \mathrm{O} \text {, oseillator paraneters } \\
\text { (as given above) ffxed }\end{array}$} \\
\hline $\begin{array}{l}t_{\mathrm{t}}=761 \mathrm{~A} \\
f_{2}=100 \% \\
\mathrm{MSE}=30\end{array}$ & $\begin{array}{l}t_{1}=943 \AA \\
f_{2}=97 \% \\
\operatorname{MSE}=5.1\end{array}$ & $\begin{array}{l}f_{1}=847 \AA \\
f_{2}=100 \% \\
\mathrm{MSE}=8.4\end{array}$ & & & \\
\hline $\begin{array}{c}t_{3}=0 \\
t_{\mathrm{i}}=775 \AA \\
\mathrm{MSE}=21\end{array}$ & $\begin{array}{l}t_{3}=4.5 \AA \\
t_{1}=936 \AA \\
\mathrm{MSE}=2.8\end{array}$ & $\begin{array}{c}i_{3}=3 \AA \\
t_{1}=847 \AA \\
\mathrm{MSE}=8.3\end{array}$ & $\begin{array}{l}t_{3}=\gamma 4 \AA A \\
t_{1}=904 \AA \\
\mathrm{MSE}=13\end{array}$ & $\begin{array}{c}t_{3}=139 \AA \\
t_{1}=473 \AA \\
M S E=15.1\end{array}$ & $\begin{array}{c}t_{3}=123 \AA \\
t_{1}=271 \AA \\
\mathrm{MSE}=0.21\end{array}$ \\
\hline $\begin{array}{l}t_{3}=37 \AA \\
t_{2}=42 \AA \\
f_{2}=50 \% \\
t_{1}=736 \AA \\
\mathrm{MSE}=24\end{array}$ & $\begin{array}{c}t_{1}=3 \AA \\
t_{2}=33 \AA \\
f_{2}=98 \% \\
t_{1}=904 \AA \\
\mathrm{MSE}=2.7\end{array}$ & $\begin{aligned} t_{3} & =26 \AA \\
t_{2} & =9 \AA \\
f_{2} & =64 \% \\
t_{1} & =841 \AA \\
M S E & =8.3\end{aligned}$ & $\begin{array}{l}t_{3}=73 \AA \\
t_{2}=20 \AA \\
f_{2}=90 \% \\
t_{1}=885 \AA \\
\mathrm{MSE}=13\end{array}$ & $\begin{array}{c}t_{3}=160 \AA \\
t_{2}=17 \AA \\
f_{2}=96 \% \\
t_{1}=450 \AA \\
M S E=15.5\end{array}$ & $\begin{array}{c}t_{3}=122 \AA \\
t_{2}=1 \AA \\
f_{2}=0.2 \% \\
t_{1}=271 \AA \\
M S E=0.21\end{array}$ \\
\hline
\end{tabular}

whether a two-layer or a three-layer analysis is used. (2) The water layer is signtly thicker when soakings are in hot water as opposed to cold water.

\section{Inoisture effects on $(200-$ and $300-W$ samples with deposition temperafures from room temperature to $\left.250^{\circ} \mathrm{C}\right)$ DLC Plims}

As indicated in the title of this section, a series of 11 sampies were prepared. For the 200-W series the depositions were at room temperature, $75,100,150,200$, and $250^{\circ} \mathrm{C}$. For the 300-W series the temperatures were at room temperature, 100,200 , and $250^{\circ} \mathrm{C}$. In this section we discuss the results of the one Lorentz oscillator model analysis when steam was directed at the surface of the sample.

Four structural models were considered, and these are combinations of finite values of $t_{1}, t_{2}, t_{3}$, and $f_{2}$ in Fig. 2 .

The resuits are summarized in Tables IV ( $200 \mathrm{~W})$ and $V$ ( $300 \mathrm{~W}$ ). If $t_{2}$ and/or $t_{3}$ don't appear in the bracketed region in the tables, then they are assumed to be zero. (For details of how the ellipsometric data analysis is carried out, see Refs. 1-4.) The mean square error (MSE) represents the quality (appropriateness) of the model fits to the experimental ellipsometric data; lower MSE means better fit. We suggest reading each table from top to bottom, one sample at a time. Taking the room-temperature $200 \mathrm{~W}$ sample first, note that the lowest MSE (for steamed sample) is for the model: water/OLC/substrate ( $t_{2}=f_{2}=0$ in Fig. 2).

The $75^{\circ} \mathrm{C} 200 \mathrm{~W}$ sample has the best solution when the $t_{2}$ layer is $99 \%$ DLC. This is compatible with the nearly comparable water/OLC/substrate solution indicating the presence of only $4.5-\AA$ water. Inspection of the solutions for the $100^{\circ} \mathrm{C} 200-\mathrm{W}$ sample are similar; there are only a few Angstroms of water on the surface with negligible penetration of the DLC.

For the 200 and $250^{\circ} \mathrm{C} 200-\mathrm{W}$ samples only two modeis were used (water/DLC/substrate and water/mixture/ DLC/substrate). In all three of these samples there were much thicker water layers: from 74 to $160 \AA$. (This is still obviously very thin!)

Table $V$ summarizes the results for the $300-\mathrm{W}$ sample series. Note that, as in the case of 200-W sample (Table IV), the model with DLC and water mixed together (with no other layers) doesn't work at all. It has a much higher MSE compared to the other models, considered in the following rows in the same table. The three remaining models give similar results; the water resides mainly on the top of DLC, with negligible "mixing" between DLC and water.

It may appear to the reader that the original thickness has been swelled by the presence of water. We don't believe this to be the case, however. Rather, the results are consistent with "vaileys" of roughness in the original structure being flled with water.

\section{SUMMARY AND CONCLUSIONS}

We have shown that variable angle spectroscopic ellipsometry is an effective tool for moisture penetration studies on a monolayer resolution scale. 
TABLE V. Moisture penetration studies (steam) of 300-W plasma deposited DLC one-nscillator model: oscillator parameters [see Eq. (3)] are in the sequence $A_{i}, P_{i}, W_{i}$ (measured in eV). For definition of $t_{1}, t_{2}$, and $t_{3}$, see Fig. 2. (If $t_{2}$ and $/$ or $t_{3}$ do not appear, then they are assumed to be equal to zero.)

\begin{tabular}{|c|c|c|c|}
\hline $\mathrm{RT}$ & $100^{\circ} \mathrm{C}$ & $200^{\circ} \mathrm{C}$ & $250^{\circ} \mathrm{C}$ \\
\hline \multicolumn{4}{|c|}{ 300-W DLC samples without $\mathrm{H}_{2} \mathrm{O}$} \\
\hline $\begin{array}{c}t_{1}=1322 \AA \\
\text { oscillator } \\
\text { parameters } \\
10.9 ; 10.9 ; 3.8 \\
\mathrm{MSE}=39.3\end{array}$ & $\begin{array}{c}t_{1}=1341 \AA \\
\text { oscillator } \\
\text { parameters } \\
10.6 ; 9.05 ; 3.8 \\
\mathrm{MSE}=39.1\end{array}$ & $\begin{array}{c}t_{1}=659 \mathrm{~A} \\
\text { oscillator } \\
\text { parameters } \\
13.02 ; 7.4 ; 3.8 \\
\mathrm{MSE}=6.6\end{array}$ & $\begin{array}{c}t_{q}=136 \AA \\
\text { oscillator } \\
\text { parameters } \\
12.6 ; 7.7 ; 3.8 \\
\text { MSE }=0.16\end{array}$ \\
\hline \multicolumn{4}{|c|}{$\begin{array}{c}\text { 300-W OLC samples with } \mathrm{H}_{2} \mathrm{O} \text { (steam), oscilhator parameters } \\
\text { (as given above) fixed }\end{array}$} \\
\hline $\begin{array}{c}t_{1}=1495 \AA \\
f_{2}=98 \% \\
\mathrm{MSE}=29.4\end{array}$ & $\begin{array}{l}f_{1}=1488 \AA \\
f_{2}=98 \% \\
M S E=52\end{array}$ & & $\begin{array}{c}t_{1}=236 \AA \\
f_{2}=60 \% \\
\text { MSE }=0.25\end{array}$ \\
\hline $\begin{array}{l}t_{3}=188 \AA \\
t_{1}=1384 \AA \\
\mathrm{MSE}=11.4\end{array}$ & $\begin{array}{l}t_{3}=175 \AA \\
t_{1}=1380 \AA \\
M S E=12.5\end{array}$ & $\begin{array}{c}t_{3}=3 \hat{A} \\
t_{1}=688 \AA \\
\mathrm{MSE}=3.7\end{array}$ & $\begin{array}{c}t_{3}=102 \AA \\
t_{1}=156 \AA \\
M S E=0.07\end{array}$ \\
\hline $\begin{array}{l}t_{2}=188 \AA \\
f_{2}=-1 \% \\
t_{\mathrm{q}}=1386 \AA \\
\mathrm{MSE}=11.4\end{array}$ & $\begin{array}{c}t_{2}=172 \AA \\
f_{2}=5 \% \\
\varepsilon_{1}=1377 \AA \\
\operatorname{MSE}=13\end{array}$ & $\begin{array}{l}t_{2}=4.5 \AA \\
f_{2}=87 \% \\
t_{\mathrm{l}}=685 \AA \\
\mathrm{MSE}=3.7\end{array}$ & $\begin{array}{c}t_{2}=113 \AA \\
f_{2}=14 \% \\
t_{1}=138 \AA \\
M S E=0.08\end{array}$ \\
\hline & & $\begin{aligned} t_{3} & =1 \AA \\
t_{2} & =9 \AA \\
f_{2} & =96 \% \\
t_{1} & =680 \AA \\
\mathrm{MSE} & =3.7\end{aligned}$ & $\begin{array}{c}t_{3}=13 \AA \\
t_{2}=101 \AA \\
f_{2}=16 \% \\
t_{1}=138 \AA \\
\mathrm{MSE}=0.08\end{array}$ \\
\hline
\end{tabular}

The main results on the DLC moisture studies are that: (1) Moisture resides mainiy on the surface of DLC no matter if it was introduced as cold water, hot water, or steam jet. (2) In cases where there is an apparent penetration $(\leqslant 50 \AA)$ we feel it likely that water is merely filling the void regions of a "rough" surface. The substrates are highiy polished oriented single-crystal (semiconductor grade) wafers. $50 \AA$ of roughness layer is reasonable for polished silicon wafers used as substrate. (3) A heat lamp removes water but not all of it. This suggests that surface micropores provide a strong surface tension for these very thin water layers. (4) The amourt of water on the surface after wetting (but without further treatment) does not depend on the parameters of deposition such as power or substrate temperature, nor does it depend on the first DLC fhm thickness in any systematic manner.

Thus, DLC is an effective protection against moisture penetration, and it can be prepared with a range of physical properties which depend on the deposition parameters. These properties are directly related to the amounts of hydrogen in the films.

\section{ACKNOWEEOGMENTS}

The research of S. Orzeszko, B. N. De, and J. A. Woollam was supported by Control Data Corporation and NASA
Lewis Grant No. NAG-3-154. Research by D. C. Ingram and J. A. Woollam was supported by the U. S. Army Materials Technology Laboratory, Contract No. DAAL 04-86-C0030 .

'R. M. A. Azzam and N. M. Bashara, Ellipsometry and Polarized Light (North-Holland, Amsterdam, 1977).

2P. G. Snyder, M. C. Rost, G. H. Bu Abbud, J. A. Woollam, and S. A. Alterovitz, J. Appl. Phys. 69, 3293 \{1986\}.

${ }^{3}$ S. A. Alterovizz, J. A. Woollam, and P. G. Snyder, Solid State Technol. 31, 99 (1988).

${ }^{4}$ G. H. Bu-Abbud, N. M. Bashara, and I. A. Woollam, Thin Solid Films $138,27(1986)$.

${ }^{5}$ T. L. Aselage, D. Emin, and C. Wood, Eds., Novel Refractory Semiconductors: Proceedings of Spring MRS, 1987 (Materials Research Society, Pittsburgh, PA, 1987), Vol. 97.

'J. C. Angus, P. Koid, and S. Domitz, in Plasma Deposited Thin Films, edited by 3. Mort and F. Jansen (CRC, Boca Raton, FL, 1986), Chap. 4. 7. Robertson, Ady. Phys. 35, 317 (1986).

IJ. A. Woollam, G. H. Bu Abbud, J. Oh, B. G. Snyder, J. D. Lamb, D. C. Ingram, and A. K. Rai, in Proceedings of the Sympositum on Dielectric Films on Compound Semiconductors, edited by V. Kapoor, D. J. Connolly, and Y. F. Wong (Electrochemical Society, Pemington, NJ, 1986), Vol. $86-3$.

"P. Koidl and P. Oelhafen, Eds., Amorphous Hydrogenated Carbon Films: Proceedings of European MRS, June 2-5, 1987 (Les Editions de Physique, ULIS-Cedex, France, 1988), Vol. 17.

IUS. A. Alterovitz, J. D. Warner, D. C. Liu, and J. J. Pouch, J. Electrochem. Soc. Solid-State Sci. Technol. 133, 2339 (1986).

"D. E. Aspnes, Thin Solid Films 89. 249 (1982).

${ }^{12}$ F. Wooten, Optical Properties of Solids (Academic, New York, 1972). 